\title{
Lung cancer mortality among the miners in a rare-earth iron mine
}

\author{
C. XING-AN ${ }^{1}$, C. YONG-E ${ }^{1}$
}

(Manuscript received 21 December 2007; accepted 4 April 2008)

\begin{abstract}
An epidemiology study on lung cancer mortality of the dust-exposed miners and dust-unexposed miners (controls) was performed in 2001. It was found that, during the period from 1977 to March 2001, 27 cases of lung cancers were observed in the dust-exposed miners, while 8 cases of lung cancers were found in controls. The SMRs of them were 6.13 and 1.90 respectively. The SMR of the dust-exposed miners was much higher than that of the controls. The difference between the two SMRs is very significant $\left(\chi^{2}=9.488, P<0.005\right)$. The probability that 27 or more lung cancers would occur in the dust-exposed group, given the expected numbers and that a total of 35 occurred is 0.0015 . The high SMR for lung cancers among dust-exposed miners likely resulted from the inhaled thorium-containing dusts (carcinogens are $\mathrm{ThO}_{2}$ and $\mathrm{SiO}_{2}$ ) and its short lived thoron progeny. This is the first evidence in humans of the carcinogenicity after long-term inhalation of thorium-containing dusts and thoron progeny. The total person-years of observation of the dust exposed miners and the unexposed miners were 62712 and 34672 respectively.
\end{abstract}

Keywords: Thorium / thoron progeny / lung cancer

RÉSUMÉ La mortalité par cancer du poumon chez les mineurs d'une mine de terres-rares et de fer.

On a effectué en 2001 une étude épidémiologique sur la mortalité par cancer du poumon de mineurs exposés à la poussière, et de mineurs non exposés à la poussière (témoins). Entre 1977 et mars 2001, on a observé 27 cas de cancers du poumon pour les mineurs exposés à la poussière, alors que, pour les témoins, on a trouvé 8 cas de cancers du poumon. Leurs RMN (rapport de mortalité normalisé) étaient de 6,13 et 1,90 , respectivement. Le RMN des mineurs exposés à la poussière était beaucoup plus élevé que celui des témoins. La différence entre les deux RMN est très significative $\left(\chi^{2}=9,488, P<0,005\right)$. La probabilité que 27 cas de cancers du poumon, ou plus, se produisent dans le groupe exposé à la poussière - compte tenu de la valeur du nombre attendu - et que le total soit de 35, est de 0,0015. La valeur élevée du RMN pour les cancers du poumon parmi les mineurs exposés à la poussière résultait vraisemblablement de l'inhalation de poussières contenant du thorium $\left(\mathrm{ThO}_{2}\right.$ et $\mathrm{SiO}_{2}$ sont des composés cancérigènes) et des descendants à vie courte du thoron. C'est la première fois que l'on met en évidence, sur l'homme, la qualité cancérigène, après inhalation à long terme, de poussières contenant du thorium et des descendants du thoron. Les nombres totaux (personne-ans) pour l'observation des mineurs exposés à la poussière et des mineurs non exposés étaient de 62712 et 34672 , respectivement.

1 National Institute for Radiological Protection, Chinese Center for Disease Control and Prevention, 2 Xinkang Street, Deshengmenwai, Beijing 100088, P.R. China. 


\section{Introduction}

The Bayun Obo Rare-earth Iron Mine is an open pit mine, which is one of the largest rare earth mine in the world. It has been worked since 1958. Its ore contains not only iron, rare-earth elements and silica dioxide but also thorium $\left(\mathrm{ThO}_{2}\right)$ at a concentration of $0.04 \%$; uranium $\left(\mathrm{U}_{3} \mathrm{O}_{8}\right)$ at a concentration of $0.0001 \% ; \mathrm{SiO}_{2}$ is found at a concentration of $10 \%$. The air concentrations of thorium-containing rare-earth and iron ore dusts in individual workshops are quite high. For example, in 1993 in the crushing workshop, the average air concentrations of dusts were in the range $1.2-16.4 \mathrm{mg} \mathrm{m}^{-3}$ (thorium 0.00192-0.026 $\mathrm{Bq} \mathrm{m}^{-3}$ ). In 1991, the air concentration of short-lived thoron $\left({ }^{220} \mathrm{Rn}\right)$ daughters in the crushing workshop was in the range of $2.7-736 \times 10^{2} \mathrm{MeV} \mathrm{L}^{-1}, 3.7-12$ times higher than that of shortlived radon $\left({ }^{222} \mathrm{Rn}\right)$ daughters in the same locations, which was $0.73-60.310^{2} \mathrm{MeV} \mathrm{L}^{-1}$. In control areas, the air concentrations of short-lived thoron daughters was in the range of $2.0-4.4 \times 10^{2} \mathrm{MeV} \mathrm{L}^{-1}$. High gamma ray exposure only occurred in mining workshops: the highest dose-rate there was $1 \mu \mathrm{Gy} \mathrm{h}^{-1}$ much higher than the average absorbed dose rate in air of China, $62 \mathrm{nGy} \mathrm{h}^{-1}$ (UNSCEAR, 2000, report P.117).

Owing to the inhaled thorium and thoron daughter products can be considered potential health hazards from analogy with the known effects of radon daughters. Meanwhile, in 1996, IARC (1996) reported that there is sufficient evidence in humans for the carcinogenicity of inhaled crystalline silica in the form of quartz or cristobalite from occupational sources. Therefore, the manager and the miners of the Bayun Obo Rare-earth Iron Mine have been very much concerned about the possibility of excess lung cancer mortality appearing among the miners after longterm inhalation of thorium-containing rare-earth dusts.

Since 1985, we have carried out three retrospective epidemiological studies of lung cancer mortalities in the miners at this mine.

A break-through result was obtained in 2001 when the total number of miners and staffs in this mine was 6983 (2 194 females). Among them, 3016 miners (891 females) were dust exposed and 3967 miners and staff members (1 293 females) were not exposed.

The results of our first epidemiology study in 1992 and the second one in 1994 has been reported (Xing-an et al., 1993, 2005).

The result of our 2001 study will be reported below. 
TABLE I

The basic performance of the electrostatic measurement system. Performances de base du système de mesure électrostatique.

\begin{tabular}{lc}
\hline Item & Value \\
\hline Counter background (counts $\left.\min ^{-1}\right)$ & 0.003 \\
$\begin{array}{l}\text { Minimum detection limit of thoron outside the body }(\mathrm{Bq}) \\
(2 \sigma \text { above zero) }\end{array}$ & 0.007 \\
$\begin{array}{l}\text { Lower limit for the detection of thorium contamination in the miners' lungs }(\mathrm{Bq}) \\
\left({ }^{224} \mathrm{Ra} \text { at the mouth) }\right.\end{array}$ & 0.068 \\
$\begin{array}{l}\text { Overall uncertainty depends on the value of the emanating } \\
{ }^{224} \mathrm{Ra} \text { at the mouth }(\mathrm{Bq})\end{array}$ & $0.037-3.7$ \\
Median coefficient of variation $(\%)$ & $\pm 0.013-0.07)$ \\
\hline
\end{tabular}

\section{Subjects and methods}

\subsection{Study population}

In this study, the dust-exposed group consisted of those having a working history longer than one year. The internal control group, the "controls", consisted of the unexposed miners and other mine staffs. All the retired persons were included in both the above two groups. During the period from 1 January 1977 to March 2001 the total person-years of observation of the dust exposed miners and the unexposed miners were 62712 and 34672 respectively.

\subsection{Exposure data}

The method used to measure exhaled thoron activity was developed in 1982 from the experience of Argonne National Laboratory in the USA (Toohey et al., 1983). It is based on electrostatic collection onto a negatively charged Mylar disc of the thoron daughter ${ }^{212} \mathrm{~Pb} 85-88 \%$ of which is positively charged. The exhaled thoron activity is expressed as the activity of the freely emanating ${ }^{224} \mathrm{Ra}$ (the parent of ${ }^{220} \mathrm{Rn}$ ) that would support the ${ }^{220} \mathrm{Rn}$ concentration measured at the subject's mouth. A conversion factor of $3.7 \mathrm{~Bq}$ emanating ${ }^{224} \mathrm{Ra}$ equivalent activity at the mouth to $37 \mathrm{~Bq}$ of ${ }^{232} \mathrm{Th}$ was used to estimate the thorium lung burden. The counter background is extremely low $\left(6\right.$ counts $\left.\mathrm{d}^{-1}\right)$ The overall uncertainty is strongly dependent on the emanating ${ }^{224} \mathrm{Ra}$ and ranges from \pm 0.013 to $\pm 0.07 \mathrm{~Bq}$ as the emanating ${ }^{224} \mathrm{Ra}$ ranges from $0.037 \mathrm{~Bq}$ to $3.70 \mathrm{~Bq}$ (Tab. I).

A total of 1301 measurements of exhaled thoron activity were carried out on 781 individuals during the period 1983-1994. Of these, 1158 measurements were performed on 638 thorium miners, and 143 measurements were made on 
143 unexposed workers (controls). In addition, during this period, 1158 medical examinations were performed on these same 638 dust-exposed miners. An epidemiological study on the mortality rates of lung cancers in the dust-exposed miners and dust-unexposed miners was carried out in 2001 (Xing-an et al., 2003).

\subsection{Vital status}

The beginning and closing dates of the follow-up were 1st January 1977 to march 2002 respectively. The vital status of the cohort was ascertained primarily through the security staff of each workshop to get the total number of miners still working and their name, age and sex; through the retired office to obtain the number of retired miners and staffs; through the office of labor union to obtain the number of deaths and their names; contact with the responsible doctor of the local miners' hospital and the hospitals in Baotou municipality to obtain the death certificates and to confirm the diagnosis, in particular, the deaths from lung cancer.

\subsection{Statistical analysis}

Person-years of follow-up were accumulated for each subject beginning with the year of first employment and the closing date of this study. The age-specific lung cancer mortality rates used to obtain the expected numbers were obtained from the book "An Investigation into Death from Cancer in China" (CPTRO, 1980).

The standardized mortality ratio (SMR) was obtained by dividing the observed number by the expected number of deaths for the lung cancers. The $95 \%$ confidence interval $(95 \% \mathrm{CI})$ of the SMR was computed with the Boice-Monson method (Boice, 1998).

The Poisson trials approach written by Ginevan (1981) was used to compare the SMR of dust-exposed miners and that of the controls.

\section{Results}

An epidemiology study on lung cancer mortality of the dust-exposed miners and dust-unexposed miners (controls) was performed in 2001. The main results are listed in Table II.

\subsection{Lung cancer mortality among dust-exposed miners and dust-unexposed miners.}

An epidemiology study on lung cancer mortality of the dust-exposed miners and dust-unexposed miners (controls) was performed in 2001. The main results are listed in Table II. 
TABLE II

Standard mortality ratios (SMRs) of lung cancers (1977-March 2001).

Rapports de mortalité normalisés (RMN) de cancers du poumon (1977 à mars 2001).

\begin{tabular}{lcccc}
\hline Group & Expected & Observed & SMR & 95\% Limits \\
\hline Dust-exposed miners & 4.406 & 27 & 6.13 & $4.20-8.94$ \\
Controls & 4.201 & 8 & 1.90 & $0.95-3.81$ \\
\hline
\end{tabular}

TABLE III

Standard mortality ratios (SMRs) of lung cancers (1977-December 1993). Rapports de mortalité normalisés (RMN) de cancers du poumon (1977 à décembre 1993).

\begin{tabular}{lcccc}
\hline Group & Expected & Observed & SMR & 95\% Limits \\
\hline Dust-exposed miners & 3.301 & 17 & 5.15 & $3.20-8.28$ \\
Controls & 3.480 & 8 & 2.30 & $1.15-4.60$ \\
\hline
\end{tabular}

Table II showed that the SMR of the dust-exposed miners and of the dustunexposed miners were greater than 1 . The SMR of the dust-exposed miners was much higher than that of the controls. The probability that 27 or more lung cancers would occur in the dust-exposed group, given the expected numbers and that a total of 35 occurred, is 0.0015. The high SMR for lung cancers among dust exposed miners likely resulted from the inhaled thorium-containing dusts (carcinogens are $\mathrm{ThO}_{2}$ and $\mathrm{SiO}_{2}$ ) and its short-lived thoron progeny. The total person-years of observation of the dust exposed miners and the unexposed miners were 62712 respectively.

Since 1994, 36 years after the initial operation of this mine, 10 additional lung cancers have appeared in dust-exposed miners. The probability that all ten of these would appear in the dust-exposed group, given the expectations in both groups during only this recent period, is 0.0066 .

The difference between the two SMRs is very significant $\left(\chi^{2}=9.488 ; \mathrm{P}<0.005\right)$, while there is no difference of smoking habits between the two groups (Tab. V).

Therefore the confounding factor cigarette smoking is excluded in the above mentioned 10 excess lung cancers.

Table III shows that even before 1994 the SMRs for both the dust-exposed and dust unexposed miners were greater than 1 . The SMR for the dust-exposed miners was more than that for the controls, and the probability that 17 or more lung cancers would occur among the dust-exposed miners given the expectations in both groups and that 25 total lung cancers appeared was marginally significant $(\mathrm{p}=$ 0.04). 
TABLE IV

A comparison of smoking history between the two groups (1994).

Comparaison de l'historique tabagique entre les deux groupes (1994).

\begin{tabular}{|c|c|c|c|c|c|}
\hline Group & Case & Smokers & $\%$ (smoker) & Smoking history (year) & Cigarettes $\left(d^{-1}\right)$ \\
\hline Crushing & 64 & 50 & 78.13 & $26.7 \pm 6.9$ & $17.8 \pm 7.4$ \\
\hline $\begin{array}{l}\text { Internal } \\
\text { control }\end{array}$ & 72 & 55 & 76.40 & $25.8 \pm 5.3$ & $19.3 \pm 7.9$ \\
\hline $\mathrm{t}$ & & & $\left(\chi^{2}=0.058\right)$ & 0.858 & 1.13 \\
\hline$P$ & & & $>0.05$ & $>0.05$ & $>0.05$ \\
\hline
\end{tabular}

Using the LUDEP (Jarvis et al., 1966) implementation ICRP publication 66 lung model it may be estimated that long term (tens of years) inhalation of thorium-232, assuming an activity median aerodynamic diameter of $5 \mu \mathrm{m}$ and class $\mathrm{S}$ solubility behavior, results in an accumulated lung burden of $0.16 \mathrm{~Bq}_{\text {per }} \mathrm{Bq}^{-1}$ of intake. We may therefore interpret the lung burden $1.6 \mathrm{~Bq}$ and reflecting a constant chronic inhalation intake of about $10 \mathrm{~Bq}^{-1}$. If we assume that the inhaled dust contains ${ }^{232} \mathrm{Th},{ }^{228} \mathrm{Ra},{ }^{228} \mathrm{Ac},{ }^{228} \mathrm{Th}$ and ${ }^{224} \mathrm{Ra}$ at secular equilibrium, an intake of $10 \mathrm{~Bq} \mathrm{y}^{-1}$ corresponds to a committed equivalent dose to lung of $3.1 \times 10^{-3} \mathrm{~Sv} \mathrm{y}^{-1}$ and the average exposure time of 32 years for the dust exposed miners indicates an average individual cumulative committed equivalent dose to lung of about $100 \mathrm{mSv}$ $\left(9.9 \times 10^{-2} \mathrm{~Sv}\right)$.

Meanwhile, smoking has been known to be a very important risk factor for lung cancer. In this study an investigation on the percentage of smokers between the highest dust-exposed miners and lower dust exposed miners was carried out. The percentage of smokers between the 64 miners (the average age was $49.3 \pm 4.8$ years old) of crushing workshop and the 72 miners (the average age was $48.0 \pm 5.6$ years old) of internal group was $78.3 \%$ and $76.4 \%$ respectively. The difference between them was not significant $\left(\chi^{2}=0.058, \mathrm{P}>0.05\right)$ (Tab. IV).

The second investigation on the percentage of smokers between the highest dust-exposed miners and not dust-exposed miners was carried out in 2008 based on the data we registered in 1985 (Tab. V).

The percentage of smokers between the 103 highest dust exposed miners (the average age was $44.17 \pm 6.65$ old years) of crushing workshop and the 94 not dustexposed miners (the average age was $43.06 \pm 6.07$ ) of internal group (of three dust free workshops) was $75.72 \%$ and $76.6 \%$ respectively. The difference between them was not significant $\left(\chi^{2}=0.0213, \mathrm{P} \gg 0.05\right)$. 
TABLE V

A comparison of smoking history between the two groups (1985). Comparaison de l'historique tabagique entre les deux groupes (1985).

\begin{tabular}{cccccc}
\hline Group & Case & Smokers & \% (smoker) & Smoking history (year) & ${\text { Cigarettes }\left(\mathbf{d}^{-\mathbf{1}}\right)}^{\text {S }}$ \\
\hline Crushing & 103 & 78 & 75.72 & $20.78 \pm 7.65$ & $14.13 \pm 6.58$ \\
Internal control & 94 & 72 & 76.60 & $19.64 \pm 8.12$ & $18.93 \pm 6.83$ \\
$\mathrm{t}$ & & & $\left(\chi^{2}=0.0213\right)$ & 0.887 & -4.3144 \\
$\mathrm{P}$ & & & $\gg 0.05$ & $\gg 0.05$ & $\ll 0.05$ \\
\hline
\end{tabular}

The results of above two investigations showed that the confounding factor citgarette smoking is excluded from the above-mentioned 10 additional lung cancers have appeared in dust-exposed miners.

The comparison results of the above three confounding factors showed that their effects on this study were negligible.

If we take a risk coefficient for lung cancer of 4.0 per $10^{4}$ person years per $\mathrm{Sv}$, based on the Hiroshima and Nagasaki Life Span Study, the 62712 person years of follow-up for the dust exposed miners, together with the an average individual cumulative committed equivalent dose to lung of $9.9 \times 10^{-2} \mathrm{~Sv}$, would lead to an expectation of 2.48 cases ( 3.0 cases).

According to $\mathrm{Xu}$ et al. (1994), the average annual exposure of 25 measurements at 8 spots of curshing workshop from thoron progeny is in the range from 0.26-5.07 WLM with an average of 1.89 WLM. Using the values of the mean excess lung cancer risk per WLM to short-lived ${ }^{222} \mathrm{Rn}$-daughters (for short-lived ${ }^{220} \mathrm{Rn}$-daughters, $1 / 3$ of that value is used) from ICRP Publication 32 (1981). The highest excess lung cancer due to 62712 person years is 1.6 cases ( 2.0 cases).

In addition, we may consider that the 8 lung cancer deaths in the control group were induced only from cigarette smoking, because the miners in the control group were not exposed to the thorium dusts. Therefore, we may also consider that among the 27 cases of lung cancer deaths in the dust exposed miners, at least 8 cases were due to the cigarette smoking. However, the person-years of the dustexposed miners were higher than that of the person-years of the miners in the control group by a factor of 1.80 . Thus, the number of lung cancer deaths among the dust-exposed miners induced by cigarette smoking would be expected to 14.4 or $\sim 14$ cases.

In 1996, IARC (1996) reported that there is sufficient evidence in humans for the carcinogenicity of inhaled crystalline silica in the form of quartz or cristobalite from occupational sources. As already mentioned above the $\mathrm{SiO}_{2}$ content of the 
dust is much higher than that of the $\mathrm{ThO}_{2}(10 \%$ vs. $0.04 \%)$. So, there is enough reason to consider $\mathrm{SiO}_{2}$ as one of the most important factors in inducing the excess lung cancer deaths among the dust-exposed miners in his mine.

According to the above-mentioned estimation, among the 27 lung cancer deaths in the dust exposed miners, 3 were induced by the inhaled thorium; 2 by the inhaled short-lived thoron daughters, 14 cases by cigarette smoking and the remaining 8.0 cases might have been induced by inhaled $\mathrm{SiO}_{2}$. The possible combined effects between $\mathrm{ThO}_{2}$ and $\mathrm{SiO}_{2}$ in such a mine would be negligible (Spiethoff et al., 1995).

In 1979, Panomareva found the enhancing effect between dust, $\mathrm{ThO}_{2}$ and chronic $\gamma$-ray exposure (Panomareva, 1979).

Therefore the combined effect of chronic $\gamma$-ray exposure and the inhaled thorium dusts could not be excluded as the cause of the excess lung cancer deaths in the exposed miners exposed in the mining workshop.

\section{Discussion}

It is a widely held view that all radionuclides, natural or man-made, are potentially harmful to humans and animals, and that they may also be carcinogens. However, much of the evidence for this comes from experimental animal studies and good evidence for carcinogenicity, or other harmful effects, in humans exposed to radionuclides under well-documented environmental or occupational conditions is often lacking. Although it has now been known for more than half a century that the stabilized thorium dioxide colloid Thorotrast, which was widely used in Europe and Japan as a radiological contrast medium for imaging the vascular and reticulosystems, could cause liver cancers and other damage, there was until recently no clear evidence for the human carcinogenicity of inhaled natural thorium dioxide. Indeed as recently as 2001 an International Agency for Research on Cancer Monograph concluded that "There is inadequate evidence in humans for the carcinogenicity of Th-232 after inhalation" (IARC, 2000).

Therefore, the increase of 10 lung cancer deaths among the 3016 dust-exposed miners during the period from January 1994 to March 2001 is the most important discovery of this epidemiological study, while no lung cancer deaths was appeared in the controls during the same period. A description of the above-mentioned 10 excess lung cancers is necessary.

1. Methods of Diagnosis. 2 were diagnosed as squamous carcinoma by pathology, 6 were diagnosed by chest X-ray radiography combined with clinical examination and 2 had incomplete data. 
2. The ages at death of the 10 workers were 55,56 ( 2 miners), $59,63,64,65,66$, 68 and 82 years.

3. The periods between exposure and death (the latency periods) were 26, 27 ( 2 miners), 28, 33 ( 2 miners), 34 ( 2 miners), 38 and 41 years.

4. Induction period, the period between the date of starting dust exposure to the date of the diagnosis of lung cancer was 35 years to 42 years, with an average of 38.5 years.

5. Smoking history (only 8 cases available, but not complete) 40 years ( 2 miners), 32 years ( 1 miner), 30 years ( 2 miners $), 10$ cigarettes $\mathrm{d}^{-1}$ ( 2 miners $), 20$ cigarettes $\mathrm{d}^{-1}$ ( 4 miners), 30 cigarettes $\mathrm{d}^{-1}$ ( 2 miners).

\section{Conclusion}

Epidemiological studies showed that excess lung cancers among the dust-exposed miners have clearly appeared since 1994, that is, 36 years after mining began at this mine, although there was some evidence of excess lung cancers before 1994. Therefore, long-term exposure to thorium-containing dusts (carcinogens are $\mathrm{ThO}_{2}$ and $\mathrm{SiO}_{2}$ ) and to thoron progeny induced an excess of lung cancers, contrary to the most recent findings from an American thorium processing plant (Liu et al., 1992). The high rate of smoking among the Bayun Obo miners (80\%) (IARC, 2000) and the high gamma-ray exposure in the mining workshops might have enhanced the carcinogenic effects of the inhaled thorium-containing dust and thoron progeny in inducing the excess lung cancers. This is the first evidence in humans of the carcinogenicity after long-term inhalation of thorium-containing dusts and thoron progeny (IARC, 2000). The confounding influence of cigarette smoking is excluded in the above-mentioned 10 excess lung cancers.

According to our estimation, among the 27 cases of lung cancer deaths in the dust exposed miners, 3 were induced by the inhaled thorium, 2 by the inhaled short-lived thoron daughters, 14 by cigarette smoking, and the remaining 8 cases might have been induced by $\mathrm{SiO}_{2}$. The possible combined effects of $\mathrm{ThO}_{2}$ and $\mathrm{SiO}_{2}$ in such a mine could be negligible. However, a combined effect of chronic $\gamma$-ray exposure and inhaled thorium dusts o the induction of lung cancer among workers in the mining workshop could not be excluded.

\section{REFERENCES}

Boice J.D. (1998) Boice-Monson method based on Rothman and Green land modern epidemiology, 2nd Ed.

CPTRO (1980) Cancer prevention and treatment research office, An Investigation into Death from Cancer in China. Health Press, China.

Ginevan M.E. (1981) Poisson trials approach to inter population comparisons of cause of death date, Environ. Res. 25, 147-159. 
IARC (1996) Monographs on the evaluation of the carcinogenic risk of chemicals of humans silica and silica compounds. CRC Press, Boca Raton, FL.

IARC (2000) Monographs on the evaluation of carciongenic risks to humans, Vol. 78: Ionizing radiation, part 2: Some internally deposited radionuclides, p. 175. IARC Press, Lyon.

ICRP Publication 32 (1981) Limits for inhalation of radon daughters by workers, Ann. ICRP 32(1).

Jarvis N.S., Birchall A., James A.C., Bailey M.R., Borrian M.D. (1966) LUDEP 2.0 personal computer program for calculating internal dose using the ICRP publication 66: respiratory tract model NRPB-SR287. NRPB, Chitton.

Liu Z., Lee T.S., Kotek T. (1992) Mortality among workers in a thorium-processing plant-A second follow-up, Scand. J. Work Environm. Health 18, 162-168.

Panomareva B.L. (1979) Long-term effect on rats of the dust-radiation factor combined with chronic $\gamma$-irradiation, Ind. Hyg. Prof. Dis. 12, 34-38 (in Russian).

Spiethoff A. et al. (1995) Interaction of thorotrast and quartz in the induction of lung tumors in rats. Health effects of internally deposited radionuclides: Emphasis on radium and thorium, G. van Kaick, A. Karaoglu, A.M. Kellerer, Eds., Health Effects of Internally Deposited Radionuclides: Emphasis on Radium and Thorium. World Scientific, Singapore.

Toohey R.E., Keane A.T., Rundo J. (1983) Measurement techniques for radium and the actinides in man at the center for Human Radiobiology, Health Phys. 44 (S1), 323-341.

UNSCEAR (2000) Sources and Effects of Ionizing Radiation, New York, volume 1.

Xing-an C., Hui-juan X., Yong-e C. et al. (1993) A follow-up study (1982-1991) on the relationship between thorium lung burden and health effects in miners at the Bayun Obo rare earth and iron mine, Radiat. Prot. Austr. 11, 157-161.

Xing-an C., Yong-e C., Hui-juan X. et al. (2003) A 20-year follow-up study on the effects of long-term exposure to thorium dust, Chin. Med. J. 116, 692-694.

Xing-an C., Yong-e C., Zhen R. (2005) Recent results from a study of thorium lung burdens and health effects among miners in China, J. Radiol. Prot. 25, 451-460.

Xu J.K. et al. (1994) As assessment of the air concentrations of radon and thoron progeny in the crushing workshop of Bayan Obo Rare-Earth Iron Mine, Chin. J. Radiol. Med. Prot. 14, $185-188$. 